\title{
Desafios do livro didático de Língua Portuguesa: o ensino do diminutivo a partir do texto
}

\section{Challenges of the textbook of Portuguese Language: teaching the usage of diminutive through texts.}

\section{Elizabeth da Silva Macena ${ }^{1}$}

RESUMO: Esta pesquisa investiga como o livro didático de Língua Portuguesa do Projeto Teláris aprovado no PNLD (Programa Nacional do Livro Didático) de 2012, aborda o uso do diminutivo no volume do $6^{\circ}$ ano do Ensino Fundamental. Constituem o corpus deste trabalho, portanto, os textos e atividades presentes em duas das unidades do volume 1 do livro didático da referida coleção. Com base nos trabalhos de Antunes (2007, 2012, 2014), Bagno (2013), Cunha e Cintra (2001) e Marcuschi (2010), foram verificadas questões referentes a como ocorre a contextualização das atividades, a importância que se dá à norma gramatical ou ao uso linguístico e o papel do texto nas propostas de atividades voltadas ao léxico e à língua. Conclui-se a partir da análise que o uso do texto como ponto de partida para o estudo da língua é bem contemplado na coleção, no entanto, esta deixa a desejar em relação à abordagem das variedades linguísticas nas atividades analisadas.

PALAVRAS-CHAVE: Livro didático. Ensino de Língua Portuguesa. Uso do diminutivo.

ABSTRACT: This work analyzes how the Portuguese language textbook of the Teláris Project approved in the 2012 PNLD (National Textbook Program, in the Portuguese acronym) addresses the use of the diminutive in the volume of the 6 th grade. The corpus of this work, therefore, consists in the texts and activities presented in two of the units of volume 1 of the textbook of the collection. Based on the works of Antunes (2007, 2012, 2014), Bagno (2013), Cunha and Cintra (2001) and Marcuschi (2010), we will assess issues such as how activities are contextualized, the importance given to grammar rules, or to the linguistic common uses and role of the text in proposals of activities concerning lexicon and language. It is concluded from the analysis that the use of the text as a starting point for the study of the language is well contemplated in the collection, however, some problems can be considered in what concerns to the approach of the linguistic varieties in the analyzed activities.

1 Mestrado Profissional em Letras (ProfLetras) pela Universidade de São Paulo. Atualmente, professora de Língua Portuguesa e Língua Inglesa do Instituto Federal de Educação, Ciência e Tecnologia de São Paulo (IFSP). Pesquisa realizada com bolsa da CAPES. Contato:elizabethmacena@hotmail.com 
KEYWORDS: Textbook. Portuguese language teaching. Use of the diminutive. O ensino de língua materna na Educação Básica

A adoção do texto como unidade básica de ensino tem sido uma estratégia amplamente discutida por muitos dos estudiosos da área, tais como Marcuschi (2010) e Antunes (2007), que defendem que dele devem, majoritariamente, partir as atividades que venham a ser planejadas para 0 ensino da língua materna. A ideia se justifica pela concepção de que toda enunciação acontece dentro de um gênero textual (Bakhtin, 1997), sendo essa a forma de que o homem se utiliza para se comunicar e que deve ser, portanto, o foco das aulas de língua materna, que visam ao desenvolvimento da competência comunicativa dos alunos. Partindo-se desse princípio, também o estudo e o tratamento da gramática apenas teriam sentido se partissem do texto ou fossem aplicados na elaboração e/ou compreensão deste. Tal concepção tem suscitado, nos últimos tempos, discussões a respeito do que se deve ou não se deve ensinar sobre gramática aos alunos.

A esse respeito Travaglia (2009) observa que surge o entendimento por parte de alguns professores de que não existe a necessidade de se ensinar gramática, que essa área de estudo não teria utilidade prática para a vida do aluno. Outra concepção, oposta, mas que da mesma forma pode ser prejudicial à formação do aluno de Educação Básica em sua língua, é a de que o ensino de Português na escola deve ser praticamente todo pautado na gramática. Nessa última concepção, o texto entraria apenas como fonte fornecedora de frases soltas a serem destrinchadas em exercícios de análise morfológica e análise sintática, conforme critica Antunes (2007). A autora traz, ainda, uma grande contribuição para essa discussão ao afirmar que:

O problema central dos cursos de línguas - materna e estrangeiras está longe de ser não ensinar gramática. É, antes, não ensinar apenas gramática; e, muito mais, é não ensinar apenas nomenclatura e classificação gramatical. Portanto, não se está propondo menos. Pelo contrário, se está pretendendo muito mais. (ANTUNES, 2007, p. 51) (grifos da autora) 
Antunes ainda defende que, na reflexão sobre a língua, existe outro aspecto de igual ou maior importância que a gramática no que concerne a prover o aluno de elementos que possibilitem o seu maior domínio dos recursos linguísticos, o estudo do léxico.

[...] me parece de extrema urgência entender que, para conseguirmos a tão apregoada competência em falar, ler, compreender e escrever, é necessário conhecer, ampliar e explorar o território das palavras, tão bem ou melhor do que o território da gramática. Os saberes sobre a gramática da língua já os temos 'internalizados' desde tenra idade. O que nunca deixa de estar sob exigências permanentes de atualização são as demandas sociais por um conhecimento lexical mais vasto, mais diversificado, mais específico, capaz de cobrir as particularidades de contextos em que acontecem nossas atuações verbais. (ANTUNES, 2012, p.14)

Segundo Batista et al. (2008), no ambiente escolar de Educação Básica, o contato dos alunos com os conhecimentos que precisa desenvolver em relação à língua portuguesa será intermediado pelo livro didático. Bunzen e Rojo (2008), ao traçarem a trajetória e evolução de materiais didáticos para ensino de língua materna no Brasil, observam que o livro didático de língua portuguesa resulta de um processo que visa a suprir as lacunas do trabalho docente.

[...] cria-se um novo tipo de material didático de apoio à prática docente que, propositalmente, interfere na autonomia do professorado. Batista $(2001,2003)$ mostra que este novo tipo de material, que conhecemos hoje como livro didático, propõe-se a estruturar e facilitar o trabalho de um professor de novo tipo, apresentando não somente os conteúdos, mas também as atividades didáticas e organizando-se conforme a divisão do tempo escolar [...] É, pois, dirigindo-se a um professor apreciado como mal formado, sem tempo para preparação e correção de atividades escolares [...] que o livro assume para si a tarefa de estruturar as aulas, até porque, muitas vezes, ele permanece mais tempo nas escolas que os próprios professores. Os autores de livros didáticos e os editores passam, portanto, a ser autores decisivos na didatização dos objetos de ensino e, logo, na construção dos conceitos e capacidades a serem ensinados. (BUNZEN; ROJO, 2008, p. 79-80) 
A partir dessas reflexões dos autores citados e a fim de verificar como ocorre a proposição de atividades voltadas aos estudos e reflexões sobre a língua nos materiais utilizados em sala de aula, investigou-se como o livro didático do Projeto Teláris de Língua Portuguesa, aprovado no Programa Nacional do Livro Didático (PNLD) de 2012 aborda o uso do diminutivo no volume do $6^{\circ}$ ano do Ensino Fundamental. Nesse sentido, foram verificadas questões referentes a:

a) como ocorrem as explicações e a inserção das atividades no livro didático e a partir de que contextos;

b) como ocorre a exploração das potencialidades do uso do diminutivo e de seu papel enquanto recurso de linguagem;

c) o papel do texto nas propostas de atividades voltadas ao léxico e à língua.

Para fins de análise, selecionou-se como objeto o uso do diminutivo, uma vez que, conforme afirmam Cunha e Cintra (2001), representa um recurso de linguagem de grande vitalidade na língua portuguesa, principalmente por meio da derivação por adição do sufixo -inho. A partir desses contributos teóricos, busca-se verificar quais aspectos do uso do diminutivo são considerados ou negligenciados no livro didático em análise.

\section{Considerações sobre a coleção}

A coleção de Língua Portuguesa do Projeto Teláris da editora Ática é de autoria de Ana Trinconi Borgatto, Terezinha Bertin e Vera Marchezi e apresenta-se em quatro volumes, atendendo do $6^{\circ}$ ao $9^{\circ}$ ano do Ensino Fundamental II.

Cada volume está organizado em quatro unidades temáticas e cada uma dessas unidades subdivide-se em dois capítulos, o que atende ao número de períodos letivos em um ano, sendo quatro bimestres e oito meses que o professor tem de efetivo trabalho, reservando-se o tempo de diagnóstico inicial, avaliações e encerramentos de períodos. 
Os capítulos estão organizados de forma mais ou menos estável, constituídos pelas seções apresentadas no quadro abaixo.

Figura 1 - Quadro da estrutura dos capítulos

\begin{tabular}{|c|c|c|}
\hline \multicolumn{2}{|c|}{ SEÇÕES } & CONTEÚDOS \\
\hline \multicolumn{2}{|c|}{ ABERTURA } & Texto para ativação de conhecimentos prévios. \\
\hline \multicolumn{2}{|c|}{ LEITURA(S) PRINCIPAL(AIS) } & Gênero a ser estudado. \\
\hline \multirow{4}{*}{$\begin{array}{l}\text { INTERPRETAÇÃO } \\
\text { DO TEXTO }\end{array}$} & Compreensão & $\begin{array}{l}\text { Predominio de questões de localização de informaçôes e/ou dados, } \\
\text { constatações, inferências simples, aspectos literais do texto. }\end{array}$ \\
\hline & $\begin{array}{l}\text { Construção do } \\
\text { texto }\end{array}$ & $\begin{array}{l}\text { Estrutura composicional e condições de produção dos gêneros } \rightarrow \\
\text { inferências sobre efeitos de sentido provocadas pela estrutura. }\end{array}$ \\
\hline & $\begin{array}{l}\text { Linguagem do } \\
\text { texto }\end{array}$ & $\begin{array}{l}\text { Escolhas de linguagem e recursos linguisticos } \rightarrow \text { inferências sobre } \\
\text { efeitos de sentido provocadas pelas escolhas linguisticas. }\end{array}$ \\
\hline & $\begin{array}{l}\text { Hora de organizar o } \\
\text { que estudamos }\end{array}$ & $\begin{array}{l}\text { Mapa conceitual para organizar o conhecimento sobre o gênero } \\
\text { estudado. }\end{array}$ \\
\hline \multirow{2}{*}{$\begin{array}{l}\text { PRÁTICA DE } \\
\text { ORALIDADE }\end{array}$} & Um bom debate & Debate para que os alunos se posicionem frente a temas propostos. \\
\hline & Outras práticas & $\begin{array}{l}\text { Atividades diversas: saraus, dramatizações, leituras expressivas e } \\
\text { dramatizadas, exposiçôes orais... }\end{array}$ \\
\hline \multirow{2}{*}{$\begin{array}{l}\text { AMPLIAÇÃODE } \\
\text { LEITURA }\end{array}$} & Outras linguagens & $\begin{array}{l}\text { Leitura orientada de obras em linguagem não verbal ou } \\
\text { verbo-visual: pintura, ilustração, foto, mapa, gráfico, quadrinhos, } \\
\text { publicidade... }\end{array}$ \\
\hline & Conexões & $\begin{array}{l}\text { Seção especialmente dedicada às relações de intertextualidade: } \\
\text { textos que dialogam com os textos principais da unidade, } \\
\text { informaçôes de apoio, curiosidades... }\end{array}$ \\
\hline \multirow{2}{*}{$\begin{array}{l}\text { LÍNGUA: USOSE } \\
\text { REFLEXÃO }\end{array}$} & $\begin{array}{l}\text { Estudos } \\
\text { linguisticos } \\
\text { e gramaticais }\end{array}$ & $\begin{array}{l}\text { Estudo sobre escolhas linguisticas realizadas nos textos estudados } \\
\text { e sobre usos e convençỗes dos modos de organização do sistema } \\
\text { da lingua portuguesa. }\end{array}$ \\
\hline & $\begin{array}{l}\text { Hora de organizar } \\
\text { o que estudamos }\end{array}$ & Mapa conceitual para organizar os conceitos linguisticos estudados. \\
\hline \multicolumn{2}{|c|}{ PRODUÇÃO DE TEXTO } & $\begin{array}{l}\text { Orais, escritos, verbais e não verbais, individuais, coletivos, em } \\
\text { duplas, de acordo com o gênero estudado. }\end{array}$ \\
\hline \multicolumn{2}{|c|}{$\begin{array}{l}\text { OUTRO(S) TEXTO(S) DO MESMO } \\
\text { GÊNERO }\end{array}$} & $\begin{array}{l}\text { Outro momento de ampliação de leitura com texto(s) do mesmo } \\
\text { gênero que foi foco do capitulo para enriquecimento de repertório. }\end{array}$ \\
\hline \multicolumn{2}{|c|}{$\begin{array}{l}\text { O QUE ESTUDAMOS NESTE } \\
\text { CAPITULO }\end{array}$} & $\begin{array}{l}\text { Sintese dos conteúdos estudados no capitulo para auxiliar a } \\
\text { autoavaliação do aluno. }\end{array}$ \\
\hline
\end{tabular}

Fonte: Borgatto, Bertin e Marchezi (2012b, p. 28-29).

Neste trabalho serão analisadas as atividades do livro didático de língua portuguesa do projeto Teláris voltadas para a abordagem do diminutivo. Esse 
assunto aparece, majoritariamente, ao longo do volume 1 da coleção, destinado ao $6^{\circ}$ ano. Chama atenção o fato de que, em vez de estar concentrado em uma única seção e esgotar-se ali, o assunto vem distribuído por diferentes capítulos e trabalhado a partir de diferentes textos. As autoras justificam essa metodologia por adotarem a progressão de conteúdos de forma espiral.

As sequências didáticas são organizadas em torno dos gêneros. No desenvolvimento da sequência em torno dos gêneros, propõem-se "recortes" de conteúdos delimitados, organizados em etapas no conjunto dos estudos para que o aluno se aproprie de conceitos específicos.

A estruturação da obra em sequências didáticas determinou uma gradação de desafios ao longo da unidade, ao longo de cada volume e ao longo da coleção.

[...]

Esse aprofundamento gradual pode também ser observado nos estudos sobre a língua, que, além de tratar dos aspectos conceituais e descritivos, associam os conteúdos aos usos encontrados na progressão de textos no decorrer da coleção. Conceitos e conteúdos são retomados sempre que necessário. [...]

Essa estruturação da obra em sequências didáticas pretende contemplar a progressão em espiral. (BORGATTO; BERTIN; MARCHEZI, 2012b, p. 15) (grifo das autoras).

Dessa forma, pela análise dos quatro volumes da coleção, foi possível verificar que o uso do diminutivo foi abordado apenas no volume 1 , voltado ao $6^{\circ}$ ano, e no volume 2, que corresponde ao 70 ano. No entanto, nesse último, encontra-se apenas uma ocorrência que constitui uma explicação e exemplificação de uso de marcas de oralidade na crônica, sem nenhuma proposta de que o aluno realize análises e atividades a respeito, portanto, essa ocorrência no segundo volume será desconsiderada neste trabalho.

Foi possível, portanto, verificar que essa questão de uso da língua foi priorizada no primeiro volume. Seguindo a proposta de progressão em espiral dos conteúdos, no livro do $6^{\circ}$ ano, o diminutivo é apresentado introdutoriamente na Unidade 1 , capítulo 1 , como recurso para caracterização das personagens do conto de abertura do capítulo. A sua próxima ocorrência se dá no Capítulo 2 do livro, a partir da análise da linguagem de outro conto popular, e a atividade 3 é sua continuação. A retomada e o aprofundamento do 
tema ocorre na Unidade 2 do livro, cujo capítulo 4, intitulado "Conto e realidade", é introduzido com o conto "A menina e as balas", de Georgina Martins, a partir do qual são propostas as atividades, também com finalidade de analisar a linguagem do texto.

\title{
A concepção de trabalho com a linguagem na coleção, segundo as autoras
}

Como se pode verificar no quadro de seções e conteúdos (figura 1), as questões de linguagem na coleção são trabalhadas em dois momentos, primeiramente, depois de um momento de leitura e, em seguida, em outra seção separadamente e de forma mais sistemática, conforme descrevem as autoras.

\begin{abstract}
Nesta coleção, os fatos linguísticos destacados, que serão objeto de estudo, são primeiramente apontados ao longo da interpretação do texto, especialmente na seção Linguagem do texto. Primeiramente, para que se deduzam os efeitos de sentido e, posteriormente, para que se tornem ponto de partida para a descrição e sistematização dessas ocorrências linguísticas. (BORGATTO; BERTIN; MARCHEZI, 2012b, p. 13)
\end{abstract}

Das atividades aqui analisadas, três estão presentes na seção Linguagem do texto em dois capítulos de unidades diferentes, como já descrito. E uma delas, a primeira, está na seção Construção do texto, em que se apresentam os elementos da narrativa e o diminutivo é utilizado para caracterizar as personagens e a linguagem utilizada por elas. Essa divisão se dá para que os fatos da língua mais relevantes sejam primeiramente trabalhados de forma a permitir a análise de qual o seu papel no texto, qual o efeito de sentido causado por eles e a sua adequação ao gênero. Essas atividades que aparecem na seção Linguagem do texto, portanto, realmente seguem o que as autoras defendem, como anteriormente colocado, ao proporcionarem, por meio da análise linguística, um melhor entendimento da construção da textualidade e de características do gênero trabalhado. 
Outro momento em que as questões de linguagem serão trabalhadas de forma mais sistemática e aprofundada na coleção será na seção Lingua: usos e reflexão. Apesar da coerência na abordagem dada pelas autoras ao trabalho com questões de linguagem que tenham o texto como objeto de análise, 0 mesmo sucesso não fica tão evidente nesta seção. Os pontos de gramática trabalhados em Língua: usos e reflexão, nem sempre conversam com os pontos trabalhados na seção Linguagem do texto.

Marcos Bagno (2013), ao analisar as coleções de Língua Portuguesa aprovadas no PNLD do Ensino Fundamental de 2008 em relação a sua abordagem das variedades linguísticas, conclui que podem ser consideradas boas coleções, que já tratam leitura e produção escrita de acordo com os mais novos estudos na área, além de apresentarem muito boa seleção de textos. 0 autor, no entanto, questiona-se por que ainda se prendem muito à abordagem transmissiva no ensino de gramática, seguindo ainda nos manuais uma tradição gramatical já ultrapassada pela sociolinguística e pela sociologia da linguagem.

O próprio autor conclui que isso ocorre, entre outros motivos, devido a uma grande pressão por parte das editoras para que o material não sofra grandes alterações a fim de reduzir custos de produção, além de atender às expectativas de agentes envolvidos e de grande influência na cultura escolar, como coordenadores, professores, pais e alunos, para os quais ainda resta a crença de que "'ensinar português' é o mesmo que 'ensinar gramática' e que 'ensinar gramática', por sua vez, é ensinar nomenclatura tradicional por meio de exercícios mecânicos de aplicação" (BAGNO, 2013, p. 18).

Esse seja, talvez, o motivo que leva as autoras do Projeto Teláris de Lingua Portuguesa a separarem a análise linguística em dois momentos distintos do capítulo, em um, já em uma tentativa de atender às teorias linguísticas contemporâneas, em outro, para não deixarem de atender às demandas de mercado e não correrem o risco de desaprovação. Para exemplificar essa constatação e para que a lista não fique muito longa e exaustiva, listam-se a seguir os conteúdos trabalhados nas seções Linguagem 
do texto e Língua: usos e reflexão apenas dos três capítulos do livro em que se aborda o uso de formas diminutivas, a cuja análise este trabalho se dedica. 
Figura 2 - Quadro de distribuição dos conteúdos de análise linguística

\begin{tabular}{|c|c|}
\hline Unidade 1: & Contos da tradição oral \\
\hline Capítulo 1: & "Causo"/ Conto \\
\hline Leitura: & O bisavô e a dentadura, Sylvia Orthof \\
\hline Linguagem do texto: & Linguagem informal e linguagem formal \\
\hline Língua: usos e reflexão & $\begin{array}{l}\text { Variedades linguísticas } \\
\quad \text { Linguagem formal e informal }\end{array}$ \\
\hline Capítulo 2: & $\begin{array}{l}\text { Conto popular em verso e conto popular em } \\
\text { prosa. }\end{array}$ \\
\hline Leitura 1: & A panela..., Pedro Bandeira \\
\hline Linguagem do texto: & Variedades linguísticas \\
\hline Leitura 2: & $\begin{array}{l}\text { Por que o morcego só voa de noite, Rogério } \\
\text { Andrade }\end{array}$ \\
\hline Linguagem do texto: & Não há essa seção para análise deste texto. \\
\hline Língua: usos e reflexão & $\begin{array}{l}\text { Frase: sinais de pontuaçã̃o. } \\
\text { A ordem das palavras nas frases. }\end{array}$ \\
\hline Unidade 2: & Conto: imaginação e realidade \\
\hline Capítulo 3: & Conto em prosa poética \\
\hline Leitura: & O sabiá e a girafa, Leo Cunha \\
\hline Linguagem do texto: & $\begin{array}{l}\text { 1. Jogos sonoros } \\
\text { 2. Ampliações ou reduções de palavras } \\
\text { próprias da oralidade } \\
\text { 3. Criação de palavras } \\
\text { 4. Sentidos }\end{array}$ \\
\hline Língua: usos e reflexão & $\begin{array}{l}\text { As frases e as palavras (I) } \\
\text { Classes de palavras: variáveis e invariáveis } \\
\text { Substantivos } \\
\text { Classificação dos substantivos } \\
\text { Próprios e comuns } \\
\text { Concretos e abstratos } \\
\text { Simples e compostos } \\
\text { Primitivos e derivados } \\
\text { Coletivos }\end{array}$ \\
\hline Capítulo 4: & Conto e realidade \\
\hline Leitura: & A menina e as balas, Georgina Martins \\
\hline Linguagem do texto: & Língua falada e língua escrita \\
\hline Língua: usos e reflexão & $\begin{array}{l}\text { As frases e as palavras (II) } \\
\text { Determinantes do substantivo } \\
\text { Adjetivo } \\
\text { Locuções adjetivas } \\
\text { Outros determinantes do substantivo } \\
\text { Artigo } \\
\text { Numeral } \\
\text { Concordância entre o substantivo e seus } \\
\text { determinantes. }\end{array}$ \\
\hline
\end{tabular}

Fonte: Elaboração própria 
Na figura 1, pode-se verificar que a subseção Linguagem do texto é uma das ramificações da seção Interpretação do texto, portanto, conforme já exposto anteriormente, dedica-se a promover uma análise de elementos linguísticos de constituição do texto a fim de promover, juntamente com outros aspectos, sua compreensão e interpretação.

\footnotetext{
O estudo da língua com base em gêneros discursivos situa e contextualiza de forma mais clara os aspectos linguísticos a ser analisados, pois vincula-os às escolhas de linguagem realizadas pelo autor na consecução de suas intenções. Com isso, o estudo gramatical ganha sentido, pois passa a dirigir a reflexão não apenas para o domínio de uma norma, mas também para o domínio das possibilidades de escolha disponíveis para o usuário da língua. ( BORGATTO; BERTIN; MARCHEZI, 2012b, p. 7)
}

Na figura 2, no entanto, percebe-se que apenas no Capítulo 1, a seção Língua: usos e reflexão se destina a sistematizar os fatos de linguagem que foram trabalhados para compreender os sentidos do gênero textual na seção Linguagem do texto. A partir do Capítulo 2, no entanto, o que se verifica é que as autoras passam a utilizar a seção Língua: usos e reflexão para atender ao conteúdo gramatical tradicionalmente previsto para $06^{\circ}$ ano. Assim, neste capítulo, contemplam os tipos de frase (verbal e não verbal) e sinais de pontuação e, nos dois capítulos subsequentes, tratam das classes de palavras, inclusive com classificações dos substantivos e listagem das outras classes de palavras de forma descontextualizada em relação aos gêneros textuais trabalhados nas respectivas unidades.

Como será possível verificar pela análise das atividades, as autoras, ainda que parcialmente, cumprem na proposição das atividades aquilo que prometem no Manual do Professor em relação a como serão trabalhados os fatos da língua na coleção. Percebe-se que, assim como defendem, elas costumam partir do texto para propor a análise do uso das formas no diminutivo. No entanto, percebeu-se necessário analisar criticamente a seleção 
de textos a partir dos quais abordam o uso do diminutivo. Isso porque o gênero a que o texto pertence e as circunstâncias em que o diminutivo ocorre nele podem revelar um posicionamento do livro didático em relação a esse fato da língua passível de ser problematizado à luz das teorias de linguagem que embasam este trabalho.

\section{Análise das atividades do livro didático}

\section{Atividade 1: Texto em estudo: "O bisavô e a dentadura" de Sylvia Orthof}

A atividade analisada a seguir encontra-se no volume 1 da coleção, portanto, no livro do $6^{\circ}$ ano. O Capítulo 1 do livro intitula-se "'Causo'/Conto" e está voltado a introduzir os elementos da narrativa. $O$ texto de abertura desse capítulo é "O bisavô e a dentadura", de Sylvia Orthof. Esse texto serve como base para as atividades de leitura a serem desenvolvidas. A atividade a seguir compõe a explicação dos elementos da narrativa apresentada pelas autoras na seção Construção do texto.

Figura 3 - Atividade 1 do livro didático

\section{Personagens}

Personagens são elementos que dão vida à história, fazendo com que ela aconteça. Muitas vezes, tanto nas narrativas orais como nas escritas, as personagens não são nomeadas, sendo identificadas por diferentes características, como as relações de parentesco.

1. Escreva em seu caderno quais são, além do bisavô Arquimedes, as personagens desse conto. Pai, mãe, avô, avó, filhos, netos, sobrinhos, afillhados, a comadre que ficou viúva, a solteirona que era irmã da avó da Mariquinha.

2. Releia alguns dos nomes de personagens que aparecem nesse conto:

$$
\text { Mariquinha Maroquinha Toninho Tia Santinha }
$$

Que tipo de relação entre as pessoas nos revelam esses nomes terminados com as formas -inho ou -inha? Prof.(a), espera-se que os alunos percebam que essas terminaçōes (diminutivos) demonstram a afetividade, o tratamento familiar, intimo.

Fonte: Borgatto, Bertin e Marchezi (2012a, p. 23) 
As questões procuram explorar um dos recursos utilizados pelo narrador para apresentação e caracterização das personagens. Pela resposta esperada dos alunos que consta no Manual do Professor, percebe-se que com essa atividade ocorre uma primeira abordagem do uso do diminutivo considerandose seu aspecto semântico de afetividade.

Para iniciar a análise dessa primeira atividade, é importante considerar que a Unidade 1 do livro, onde a atividade se encontra, trata de contos da tradição oral. $\mathrm{Na}$ introdução do capítulo 1 , explica-se que a história que virá a seguir é um "causo", narrativa popular que passa de geração para geração, que foi recontada por Sylvia Orthof, por escrito, mas que mantém muitas características próprias da fala (BORGATTO; BERTIN; MARCHEZI, 2012a, p.18).

Ao longo do capítulo, em relação à linguagem, serão trabalhados aspectos relacionados ao uso da língua na modalidade formal e na modalidade informal. Assim, a seção Língua: usos e reflexão tem como título Variedades linguísticas e subtítulo Linguagem formal e informal. Para as autoras, o uso da linguagem formal ou da linguagem informal se dará em função de diferentes fatores, entre os quais, citam: a situação comunicativa, que envolve a circunstância, o interlocutor e a intenção; a região do falante; e o grupo social do falante (BORGATTO; BERTIN; MARCHEZI, 2012a, p. 30).

Ao verificar como ocorre essa abordagem pelas autoras, cabe aqui evocar Bagno (2013) que analisa uma tendência dos livros didáticos de língua portuguesa a mesclarem termos que, para a sociolinguística, são bem distintos e que podem imprimir preconceitos em relação a algumas variedades linguísticas ao atribuir-Ihes a feição de informalidade.

Também é visível nos LD a tendência a tratar da variação linguística em geral como sinônimo de variedades regionais, rurais ou de pessoas não escolarizadas. Parece estar por trás dessa tendência a suposição (falsa) de que os falantes urbanos e escolarizados usam a língua de um modo mais uniforme, mais "correto", mais próximo do padrão, e que nesse uso não há variação. De fato, como vamos ver, a variação presente nas normas urbanas de prestígio é sistematicamente atribuída à "informalidade", o que é um tremendo equívoco de análise. (BAGNO, 2013, p. 82) 
Para o autor, essa carência de acuidade teórica pode levar os alunos a construírem a ideia equivocada de que "variação é coisa de caipira", para utilizar suas próprias palavras. Apesar de não ser o foco deste trabalho criticar a forma como as autoras tratam questões teóricas mais profundamente, traçar os aspectos contextuais em que a atividade em questão ocorre é importante para compreender que tipo de leitura se pode fazer dela.

Com respaldo nas contribuições de Bagno, pode-se fazer a avaliação de que o fato de "O bisavô e a dentadura" tratar-se de um conto popular, cuja história ocorre no interior de Minas Gerais, pode influenciar a forma como os alunos julgarão o uso do diminutivo, levando-os a associa-lo ao fato de o grupo que pratica essa variedade não gozar de prestígio social.

\section{Atividade 2: Texto em estudo: "A panela..." de Pedro Bandeira}

A atividade ora analisada encontra-se no Capítulo 2 do livro, intitulado "Conto popular em verso e conto popular em prosa". Como se pode verificar pelo título, este capítulo se dedicará a explicar, analisar e trabalhar os elementos característicos e constituintes desses gêneros textuais. A explicação e as questões que seguem representam a primeira parte da seção Linguagem do texto, que, no presente capítulo, está voltada para o tema Variedades linguísticas, sendo esse o subtítulo da seção.

$\mathrm{O}$ texto que introduz esse capítulo é o conto de Pedro Bandeira "A panela do diabo", renomeado como "A panela..." para fins didáticos. É dele que são retiradas as palavras e expressões analisadas nos exercícios 1 e 2 a seguir.

Figura 4 - Atividade 2 do livro didático 
No conto "A panela...", há os seguintes casos de uso da linguagem informal:

\section{(1) Uso de diminutivos}

1. Observe algumas palavras do conto usadas com a terminação-inho/-inha:

"fazer uma comprinha"; " "foi provar da panelinha"; "estava bem quentinha"; "qualquer caldinho ralo".

Essas palavras estão na forma do diminutivo. Das palavras no diminutivo destacadas, escreva no caderno:

a) as que estão ligadas à ideia de carinho, afeto, valorização; Panelinha, quentinha.

b) as que estão ligadas à ideia de pouco-caso, desprezo. Comprinha, caldinho.

2. Releia:

"... num joguinho o Zé Trabuco

com trapaça nos venceu"

Nesse caso, o diminutivo joguinho está associado a qual ideia: afeto ou desprezo?

Por quê? Prof.(a), espera-se que o aluno perceba que a palavra foi usada no sentido de pouco-caso, de desprezo, porque foi um jogo sujo.

Geralmente o diminutivo está associado à ideia de coisas pequenas, menores que o normal. Exemplos: mesinha, ratinho, bolinha.

Mas na linguagem mais informal pode estar associado às ideias de:

- carinho, afeto, valorização, como em: paizinho.

- pouco-caso, desprezo, ironia, como em: gentinha.

Fonte: Borgatto, Bertin e Marchezi (2012a, p. 48).

\section{Exercício 3}

Este exercício vem na página seguinte à dos exercícios 1 e 2 e está relacionado com eles, como se verifica no enunciado. Pede-se, aqui, que o uso do diminutivo nas tiras seja comparado com o uso feito no conto "A panela..."

Figura 5 - Exercício 3 da atividade 2 do livro didático 
Atividade: variedades linguísticas

Observe o uso de diminutivos nas tirinhas abaixo e compare com o uso feito no conto "A panela...":

\section{Tirinha 1}
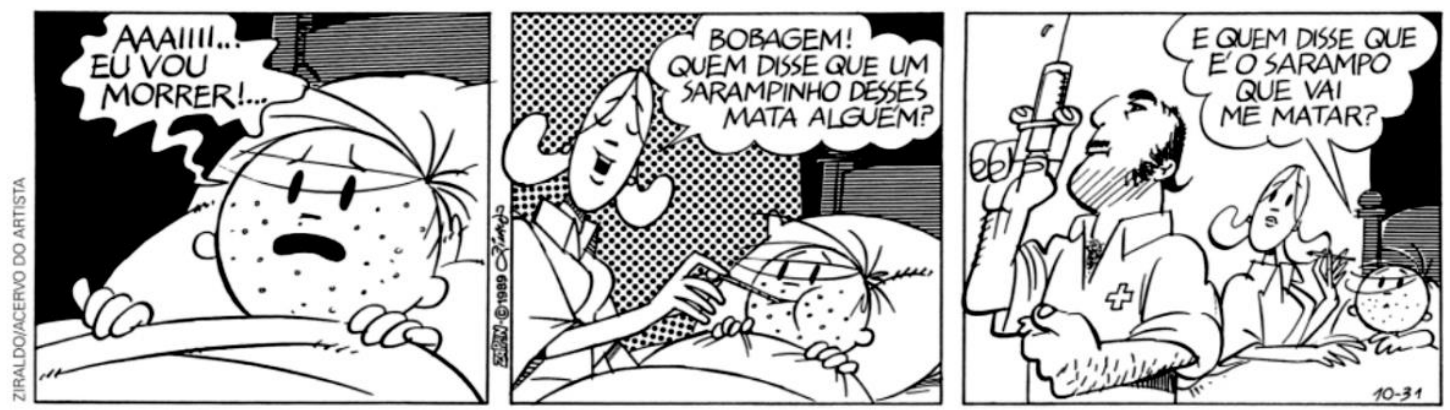

Tirinha 2
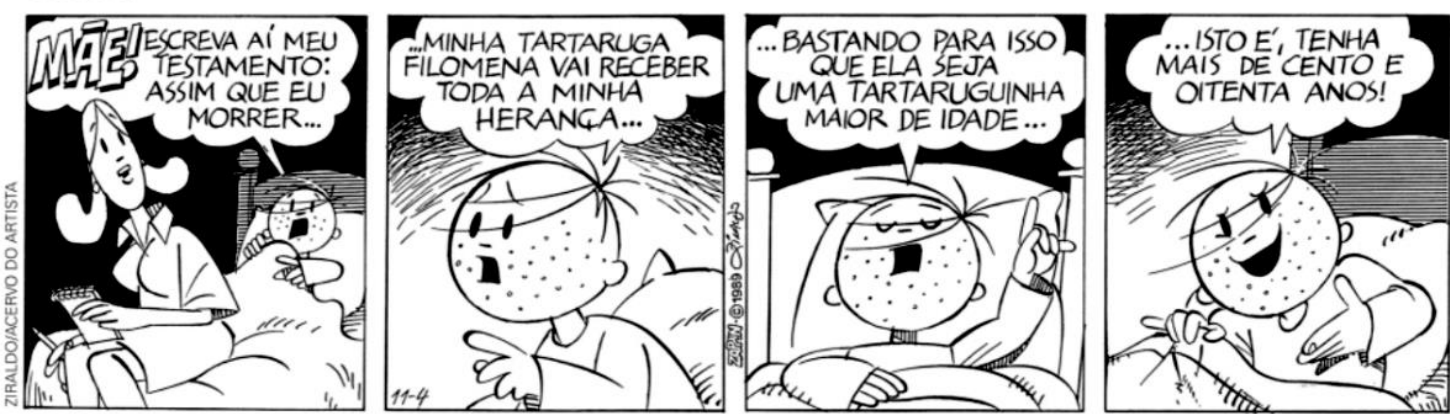

ZIRALDO. As melhores tiradas do Menino Maluquinho. São Paulo: Melhoramentos, 2000. p. 19-21.

Observe as palavras: sarampinho e tartaruguinha.

Responda no caderno qual delas foi usada com a ideia de:

- afeto, carinho? Tartaruguinha.

- ironia, algo sem importância? Sarampinho.

Fonte: Borgatto, Bertin e Marchezi (2012a, p. 49)

Os textos em que se baseia a referida atividade são duas tirinhas de Ziraldo em que a personagem Menino Maluquinho interage com sua mãe, tendo de identificar qual o efeito semântico causado pelo uso das formas "tartaruguinha" e "sarampinho" no diminutivo.

É importante verificar em que contexto cada uma das palavras ocorre. Em "A panela...", a personagem folclórica de Pedro Malasartes ajuda dois tropeiros que haviam sido enganados pelo trapaceiro Zé Trabuco a recuperarem seus pertences. No início da história, Zé Trabuco encontra dois tropeiros e propõe um jogo de truco, ao trapacear no jogo, ele consegue ganhar o dinheiro e as mulas dos tropeiros. Na vila, os tropeiros encontram 
Malasartes, contam-Ihe a história e pedem ajuda. Este, então, engendra um plano, compra um pouco de feijão, temperos e uma panela, vai até a estrada onde passará Zé Trabuco, cozinha o feijão, apaga o fogo e faz Trabuco pensar que a panela cozinhava sozinha. $\mathrm{O}$ trapaceiro acredita na história e paga pela panela com o dinheiro e as mulas que havia ganhado desonestamente dos tropeiros.

As palavras no diminutivo utilizadas na atividade estão nas estrofes a seguir. Os destaques feitos nas palavras são para fins de análise, não constam no original.

Os tropeiros contam a Malasartes o que aconteceu:

\section{- Pedro amigo nos ajude! \\ Veja só o que aconteceu:}

num joguinho, o Zé Trabuco

com trapaça nos venceu. (BORGATTO; BERTIN; MARCHEZI, 2012a, p. 45)

Na sequência, Pedro vai à venda comprar os itens de que precisa para executar seu plano:

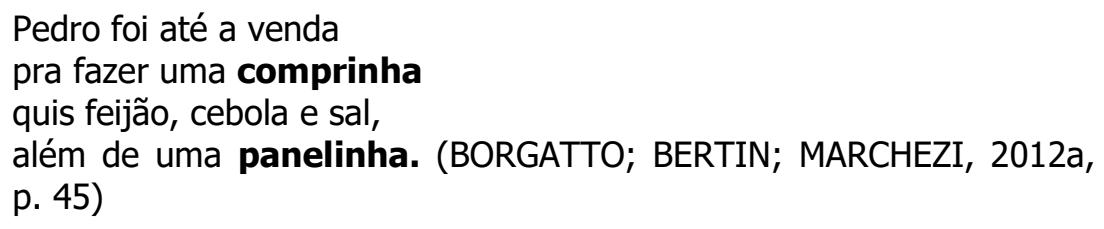

Ao ser questionado por Trabuco sobre o que estava fazendo com aquela panela, Pedro diz que ela era mágica e que cozinhava sem fogo, acrescenta que acabara de preparar um pouco de feijão e pede que ele prove.

Zé Trabuco se abaixou, foi provar da panelinha. Descobriu que estava cheia e que estava bem quentinha. (BORGATTO; BERTIN; MARCHEZI, 2012a, p. 45) 
Ao acreditar que a panela era mágica, Zé Trabuco resolveu comprá-la de Malasartes pelo seguinte motivo:

\author{
A bendita da panela, \\ com qualquer caldinho ralo, \\ a enganar a toda gente \\ haveria de ajudá-lo. (BORGATTO; BERTIN; MARCHEZI, 2012a, p. 45)
}

Como se verifica na figura 4, o Manual do Professor indica que os termos "panelinha" e "quentinha" estariam ligados à ideia de carinho, afeto e valorização. Ao se verificar o contexto em que a palavra "panelinha" foi utilizada, no entanto, não fica clara a intenção de referência à palavra com carinho ou valorização. $\mathrm{O}$ termo parece mais estar se referindo ao fato de esta ser apenas uma panela pequena mesmo, portanto, o diminutivo estaria indicando o tamanho reduzido da panela. Essa interpretação pode levar boa parte dos alunos a associarem o tamanho reduzido a algo sem importância ou de pouco valor, o que encontra respaldo na observação em relação ao fato de alguns sufixos diminutivos terem assumido sentido pejorativo, sobre o que Coutinho (1982, p. 241) afirma que "à ideia de pequenez por vezes se ajuntou a de coisa ridícula."

Quanto ao termo "quentinha", tampouco deixa transparecer, no trecho do texto em que aparece, a ideia de carinho ou afeto. As autoras não deixam claro a que tipo de "valorização" se referem, mas é possível inferir que essa seja uma ocorrência do que cita Said Ali (1971, p. 55), para quem "em alguns casos o adjetivo em -inho é usado com valor de superlativo".

Outro termo que também merece ser comentado é "caldinho", o qual o Manual do Professor indica que expressa a ideia de pouco-caso, efeito semântico facilmente observável pelo contexto. Se observado o entorno do termo na estrofe, nota-se o fato de ele vir seguido por um adjetivo que indica qualidade negativa e por pronome indefinido "qualquer caldinho ralo", e esses reforçam a ideia de que o diminutivo está sendo usado em sentido pejorativo. 
No exercício 3 (figura 5), há apenas dois termos a serem categorizados. Pode-se, no entanto, observar que o termo "tartaruguinha" poderia também ser classificado na segunda opção, pois pode exprimir a ideia de ironia, visto que uma tartaruga de 180 anos ser referenciada com uso do diminutivo não seria necessariamente adequado. Apesar de não fazer muito sentido o fato de dizer "sarampinho" com intenção de demonstrar afeto ou carinho à doença.

\section{Atividade 3: Texto em estudo: "A menina e as balas" de Georgina Martins}

A Unidade 2 do livro, intitulada "Conto: imaginação e realidade", está composta por dois capítulos, o capítulo 3 trata de conto em prosa poética, a atividade que ora será analisada está presente no capítulo 4, intitulado "Conto e realidade". O texto de introdução do capítulo é o conto "A menina e as balas", de Georgina Martins. É a partir desse texto que são propostas as atividades que se encontram na seção Linguagem do texto.

Figura 4 - Atividade 3 do livro didático

3. Por que a narradora se refere à menina usando sempre o diminutivo: garotinha, menininha? 0 diminutivo é usado como forma afetiva de tratamento e revela

4. Observe as frases do conto lido em que foram usados substantivos no diminutivo:

"[...] perto de uma pracinha [...]."

"Eu sempre gostei de furar latinhas de leite condensado [...]."

"[...] ela os pegava em uma lojinha [...]."

"[...] seus olhinhos brilharam [...]."

Que palavras foram usadas no diminutivo para indicar:

a) o tamanho pequeno de algo? Pracinha, latinhas, lojinha

b) afetividade, carinho? Ollhinhos 
5. Leia agora uma frase em que a menina usa um adjetivo na forma diminutiva:

"Ele sempre conta quanto dinheiro tem e tem que ter tudo certinho."

Nessa frase, a menina usou o diminutivo com a mesma intenção de indicar tama-

nho ou afetividade? Não. O diminutivo foi usado para indicar intensidade ou precisão; a menina

6. Na frase:

"Minha querida, vou lhe explicar direitinho [...]"

a narradora-personagem usou a palavra direito na forma diminutiva com a mesma intenção da menina? Sim, a intenção foi indicar intensidade, precisão. substantivo, pode indicar tamanho pequeno de algo, afetividade, carinho; no do adjetivo, intensidade ou modo.

Fonte: Borgatto, Bertin e Marchezi (2012a, p. 103).

O conto "A menina e as balas" narra a história de uma criança que vive em situação de miséria com a mãe, o padrasto e seis irmãos e que precisa trabalhar vendendo doces para ajudar a família. Um dia, na volta do cinema onde havia assistido a um filme comovente sobre crianças na mesma situação que aquela menina, a narradora decide ajudá-la pagando pelos doces que ainda restavam, mas sem levá-los, para que assim a menina pudesse revendê-los no dia seguinte e ter mais lucro. A menina não entende a intenção da mulher e insiste que esta leve os doces, pois diz que não podem sobrar doces em sua caixa ou sua mãe briga e seu padrasto a castiga. A narradora, por fim, vê-se obrigada a levar os doces e a menina vai embora contente.

O primeiro exercício da atividade ora analisada questiona por que a narradora sempre se refere à menina no diminutivo. Segundo o Manual do Professor, esse tratamento revela comoção e compaixão da mulher em relação à criança. Pode-se, no entanto, considerar que esse tratamento se deve ao fato de a personagem ser uma criança de apenas oito anos e que, portanto, 0 diminutivo estaria fazendo referência ao seu tamanho.

É possível notar que a leitura do texto permite a interpretação indicada pelo Manual do Professor, a própria narradora cita esse sentimento no seguinte trecho: 
Contei o dinheiro que eu tinha na bolsa e cheguei à conclusão de que dava para pagar todos os doces que ainda restavam. Depois de ver um filme como aquele, eu achava impossível deixar uma menininha daquelas cochilando no meio da rua, numa noite fria. (MARTINS, 2003, apud BORGATTO; BERTIN; MARCHEZI, 2012a, p. 100).

No entanto, a interpretação de que as formas diminutivas representam o tamanho pequeno da menina também pode ser inferida do texto. Apesar de o julgamento de dimensões de certos seres ser relativo, ao considerar-se uma criança de oito anos que trabalha é possível sim que seja considerada pequena, ainda que essa pequenez esteja mais relacionada com sua idade do que propriamente com sua altura.

Um aspecto importante do uso do diminutivo nessa situação que não foi considerado pelas autoras é aquele que diz respeito à caracterização de uma variante de gênero. Mendes (2012, p. 113), ao realizar um experimento sociolinguístico a fim de verificar a hipótese surgida em um de seus trabalhos anteriores de que "o uso de diminutivos guarda correlação com categorias de sexo/gênero" conclui que:

Os resultados resumidos na Tabela 1 sugerem que a percepção de
que "mulheres usam diminutivos de maneira exagerada" tem um
correlato na produção linguística (os usos, propriamente), tanto numa
dimensão quantitativa [...] quanto numa dimensão qualitativa [...].
Assim, se por um lado pode-se dizer que a avaliação de "exagero"
emergiu experimentalmente e foi coloquialmente enunciada, por
outro, as análises dos usos de diminutivos aqui apresentadas parecem
confirmar a hipótese de que eles podem funcionar como marcadores
de sexo/gênero. (MENDES, 2012, p.123)

Portanto, se existem indícios, inclusive com base em estudos, de o uso de formações diminutivas serem mais frequentes na fala feminina, pode-se considerar que esse aspecto foi pouco explorado nas atividades propostas. Tanto no exercício 3 da atividade 2 como neste primeiro exercício da atividade 3, o uso do diminutivo ocorre em situações de interlocução que envolvem mulheres e crianças, o que não foi citado nem considerado pelas autoras em nenhum deles. 


\section{Análise das atividades propostas}

Após a análise das propostas de atividades em relação ao uso do diminutivo no livro do $6^{\circ}$ ano, pode-se refletir sobre a eficiência com que 0 assunto foi tratado ao longo do volume, considerando-se aquilo que as autoras propõem como objetivos do trabalho com questões de reflexão sobre a língua na coleção.

O estudo gramatical se tornará mais significativo uma vez que deixa de ser apenas a apropriação de uma norma, isto é, ele passa a dirigir uma reflexão sobre usos reais da língua, enriquecendo as possibilidades de escolha da linguagem adequadas a cada situação comunicativa. (BORGATTO; BERTIN; MARCHEZI, 2012b, p. 6)

Em relação às diversas possibilidades de escolha de uso da linguagem de que o usuário dispõe, consideramos que as autoras deixam a desejar em relação à abordagem do uso do diminutivo, pois apenas algumas de suas nuanças podem ser exploradas visto que os textos em que aparecem apenas permitem a análise do uso de formas diminutivas em um número limitado de situações.

Ao dedicar uma leitura mais crítica aos textos e às atividades propostas quanto ao uso do diminutivo, percebe-se que os aspectos semânticos e estilísticos destacados são poucos e repetitivos. Além disso, os gêneros textuais escolhidos para abordagem do fato da língua em questão, também revelam um viés de julgamento do uso do diminutivo como se fosse adequado apenas nessas situações restritas.

$\mathrm{Na}$ primeira atividade analisada, que parte do texto "O bisavô e a dentadura", assim como no exercício 3 da atividade 2, que analisa o diminutivo nas tirinhas da personagem de Ziraldo, o uso do diminutivo se dá entre familiares, entre os quais, mulheres e uma criança. Em ambas as atividades, destaca-se o efeito semântico de afetividade expresso pelo seu uso. Outra intersecção nesse sentido ocorre entre esse exercício e os exercícios da 
atividade 3, que partem do texto "A menina e as balas". No caso das tirinhas, 0 diminutivo é usado pela mãe do Menino Maluquinho e pelo garoto e, no caso da história de Georgina Martins, é usado pela narradora-personagem. Note-se, ainda, que ambos os casos representam situações de interlocução entre mulheres e crianças, o que pode ressaltar uma propriedade do diminutivo como caracterizador do discurso feminino e infantil, principalmente se considerarmos o que observa Antunes.

A ideia de que a interação verbal é contextualizada já não constitui nenhuma novidade. É consensual o princípio de que toda ação de linguagem acontece em determinado contexto. Maingueneau (2001) concebe esse 'contexto' também em termo de 'cenas' [...] Nessa perspectiva, o conceito de 'cena' parece bastante esclarecedor e sugestivo do que, de fato, acontece quando interagimos verbalmente, pois reforça a compreensão de que o uso da linguagem mobiliza um esquema que, já validado na memória cultural do grupo, implica atores e ações que interagem em um determinado espaço de atuação (a cena). (ANTUNES, 2012, p. 58)

O conceito de 'cenas' de Maingueneau, citado pela autora, corrobora a análise aqui feita de que o fato de se colocar sempre os mesmos perfis de personagens em situações de interlocução restritas para exemplificar o uso do diminutivo pode fazer entender que ele deve se restringir apenas a essas situações comunicativas e que é mais característico de uma ou outra variedade linguística. Pode-se, assim, observar que essa pouca variedade de situações das quais se parte para abordar essa questão, deixa de contribuir para a ampliação das possibilidades de escolha do aluno para um uso mais expressivo da língua.

Outro aspecto interessante a ser analisado quanto à seleção de textos feita pelas autoras é em relação àqueles que elas classificam como contos populares. Como se pôde verificar, o primeiro texto trabalhado foi o "causo" de Sylvia Orthof, que se passa no interior de Minas Gerais, nesse capítulo, a reflexão sobre a língua introduz a temática das variedades linguísticas. 0 capítulo 2 faz parte ainda da Unidade 1: contos da tradição oral. O texto de abertura do capítulo é "A panela do diabo", recontado em verso por Pedro Bandeira. Essa atividade, assim como a anterior, ocorre na seção Linguagem do 
texto, que também tem o subtítulo Variedades linguísticas. Como as autoras praticam a progressão de conteúdos em espiral, entende-se que esta seção intenta aprofundar o que fora introduzido sobre o tema no capítulo anterior.

Dessa forma, na continuação do tema Variedades linguísticas, as autoras explicam que:

Entre as variedades linguísticas existentes - regional, de grupos sociais, de idade, de gênero, etc. - há duas formas que estão sempre presentes:

- formal, chamada de variedade-padrão, utilizada de acordo com as regras da gramática normativa;

- informal, utilizada em roda de amigos, entre familiares e em situações em que a linguagem não precisa seguir regras

[...] rígidas da linguagem considerada padrão.

No conto "A panela...", há os seguintes casos de uso da linguagem informal: (BORGATTO; BERTIN; MARCHEZI, 2012a, p.49) (grifo das autoras).

As autoras seguem a explanação com os seguintes itens: 1 Uso de diminutivos; 2 Uso de palavras próprias da linguagem popular; 3 Redução de palavras; e 4 Outras expressões da linguagem popular. $O$ uso do diminutivo, nessa seção, portanto, está associado à linguagem informal e, como se pode perceber por alguns elementos do enredo (mulas, tropeiros, a vila), também, acontece fora de uma área urbana, então, novamente, sugere o pertencimento a uma variedade regional. $\mathrm{O}$ fato de se atribuir a variedades regionais o rótulo da informalidade, além de poder reforçar o preconceito contra ela e seus usuários, ainda apresenta, segundo Bortoni-Ricardo, um equívoco de análise.

Em toda comunidade de fala onde convivem falantes de diversas variedades regionais, como é o caso das grandes metrópoles brasileiras, os falantes que são detentores de maior poder - e por isso gozam de mais prestígio - transferem esse prestígio para a variedade linguística que falam. Assim, as variedades faladas pelos grupos de maior poder político e econômico passam a ser vistas como variedades mais bonitas e até mais corretas. (BORTONI-RICARDO, 2004, p. 34) 
Outro fato que se pode questionar sobre a contextualização dessas atividades é o de que o uso de apenas textos de ficção e, em especial, contos da tradição oral e narrativas literárias tenham sido usados como textos onde o diminutivo pode ocorrer. Isso pode passar ao aluno a ideia equivocada de que apenas em tais gêneros o uso do diminutivo é adequado.

Ressalte-se ainda o fato de as autoras terem escolhido trabalhar 0 diminutivo apenas a partir de textos nos quais variedades linguísticas regionais são proeminentes ou em que as personagens que utilizam o diminutivo são mulheres, familiares próximos ou crianças, possivelmente, passe a ideia de que o diminutivo seria apenas informal, afetivo ou mais característico da linguagem feminina ou regional. No entanto, ainda assim, em relação a esses dois últimos aspectos nada é evidenciado nas explicações constantes do livro, cabendo ao professor fazer uma leitura mais detalhada e chamar atenção dos alunos para isso.

Como as próprias reflexões e estudiosos invocados neste trabalho afirmam, nenhuma dessas características do uso do diminutivo está equivocada, no entanto o fato de aparecerem repetidamente e sempre as mesmas a serem abordadas e ressaltadas na atividade não reflete a grande produtividade e vitalidade que as formações no diminutivo apresentam na língua segundo os estudiosos citados, tais como Sandmann (1988) e Cunha e Cintra (2001).

\section{Considerações finais}

Os livros didáticos representam um instrumento que atualmente ocupa uma posição contraditória na escola. Por um lado, muitos professores o têm como aliado em sua prática docente, por ajudá-los a contornar as dificuldades da profissão - como as condições de trabalho precárias, a falta de recursos materiais e as múltiplas jornadas para complementar os baixos salários - que permitem pouco tempo de preparação de aulas. Por outro lado, estudiosos e até mesmo alguns dos mesmos professores reconhecem suas deficiências em 
diversos aspectos, tais como a desconsideração dos conhecimentos prévios de cada turma, as poucas possibilidades de diálogo com as diferentes realidades de cada comunidade escolar e, por vezes, abordagens deficientes de um ou outro componente essencial para desenvolvimento da plena competência comunicativa dos alunos.

Diante dessa realidade, cabe ao professor procurar alternativas para tornar sua prática mais significativa, consciente e embasada, ainda que dentro de suas possibilidades. Foi com tal finalidade que se colocou em discussão uma questão de linguagem de grande vitalidade no português brasileiro, verificando como o livro didático possibilita sua exploração, evidenciando quais as potencialidades e os limites de sua abordagem.

A etapa de análise de como se dão os estudos de linguagem no livro didático revelou que o assunto específico analisado nesta pesquisa, o uso de palavras no diminutivo, está trabalhado no livro sempre a partir do texto, com finalidade de analisá-lo enquanto elemento de constituição da textualidade e, muitas vezes, como caracterizador do gênero. Esse, pode-se considerar, é um aspecto positivo do livro didático, pois propõe a análise linguística contextualizada, como pregam as atuais teorias de ensino de língua materna. Todavia, também foi possível constatar que as autoras mantém em cada capítulo do volume outra seção que aborda outros tópicos gramaticais de forma descontextualizada, seguindo a ordem da abordagem tradicional.

Como se pôde verificar a partir das atividades analisadas, o livro didático, apesar de já trabalhar, ao menos em parte, em consonância com as teorias que tratam do estudo e do ensino de língua materna, mostrou-se pouco eficaz em promover uma compreensão mais ampla e contextualizada a respeito do uso do diminutivo com fins estilísticos e expressivos. As atividades que abordam o uso do diminutivo ao longo do volume do $6^{\circ}$ ano, em grande parte, envolvem sempre os mesmo tipos de situações comunicativas, o que restringe as possibilidades de análise e posterior aplicação pelos alunos desse recurso expressivo. 
Em relação ao uso do texto como ponto de partida das atividades de análise linguística, foi possível verificar que as autoras conseguem atender a essa demanda que atualmente rege o ensino de língua. A seleção de textos, todavia, majoritariamente contos populares, sugere que o uso de palavras no diminutivo esteja mais relacionado com variedades linguísticas regionais, como ocorre, no capítulo 1 do livro em foco, ao tratar de variedades linguísticas. De acordo com teóricos estudados, a abordagem dada no livro pode inclusive levar a equívocos de análise de certos fenômenos linguísticos e ao reforço de estereótipos que induzem o preconceito linguístico. Esse fato pode trazer efeitos negativos ao ensino se negligenciado pelo professor, mas também pode ser contornado pelo docente que esteja preparado para lidar com esse material, fazendo as intervenções necessárias, aproveitando dele o que convém e complementando-o no que for deficitário.

\section{Referências}

ALI, Manuel Said. Gramática Histórica da Língua Portuguesa. 7. ed. Rio de Janeiro: Livraria Acadêmica, 1971.

ANTUNES, Irandé. Muito além da gramática: por um ensino de línguas sem pedras no caminho. São Paulo: Parábola, 2007.

. Território das palavras. estudo do léxico em sala de aula. São Paulo. Parábola, 2012.

. Gramática contextualizada: limpando "o pó das ideias simples". São Paulo: Parábola, 2014.

BAGNO, Marcos. Sete erros aos quatro ventos: a variação linguística no ensino de português. São Paulo: Parábola, 2013.

BAKHTIN, Mikhail. Os gêneros do discurso. In: Estética da criação verbal. São Paulo: Martins Fontes, 1997, p. 277-327.

BANDEIRA. Pedro. A panela... In: BORGATTO, Ana Maria Trinconi; BERTIN, Terezinha Costa Hashimoto; MARCHEZI, Vera Lucia de Carvalho. Português $6^{\circ}$ ano. Projeto Teláris. São Paulo: Ática, 2012. 
BATISTA; Antonio Augusto Gomes; ROJO, Rosane; ZÚÑIGA, Nora Cabrera. Produzindo livros didáticos em tempo de mudança (1999-2002). In: VAL, Maria da Graça Costa; MARCUSCHI, Beth (Orgs.). Livros didáticos de língua portuguesa: letramento, inclusão e cidadania. Belo Horizonte: Ceale; Autêntica, 2008. p. 47-72.

BORGATTO, Ana Maria Trinconi; BERTIN, Terezinha Costa Hashimoto; MARCHEZI, Vera Lucia de Carvalho. Português - $6^{\circ}$ ano. Projeto Teláris. São Paulo: Ática, 2012a. Ática, 2012b. . Português - $6^{\circ}$ ano. Projeto Teláris. Manual do Professor - São Paulo:

BORTONI-RICARDO, Stella Maris. Educação em língua materna: a sociolinguística na sala de aula. São Paulo: Parábola, 2004.

BUNZEN, Clécio; ROJO, Roxane. Livro didático de língua portuguesa como gênero do discurso: autoria e estilo. In: VAL, Maria da Graça Costa; MARCUSCHI, Beth (Orgs.). Livros didáticos de língua portuguesa: letramento, inclusão e cidadania. Belo Horizonte: Ceale; Autêntica, 2008. p. 73-117.

COUTINHO, Ismael de Lima. Pontos de Gramática histórica. Rio de Janeiro: Ao Livro Técnico, 1982.

CUNHA, Celso; CINTRA, Lindley. Nova Gramática do Português Contemporâneo. 3.ed. Rio de Janeiro: Nova Fronteira, 2001.

MARCUSCHI, Luiz Antônio. Gêneros textuais: definição e funcionalidade. In: DIONISIO, Angela Paiva; MACHADO, Anna Rachel; BEZZERA, Maria Auxiliadora. (Orgs). Gêneros textuais e ensino. São Paulo: Parábola, 2010.

MARTINS, Georgina. A menina e as balas. In: BORGATTO, Ana Maria Trinconi; BERTIN, Terezinha Costa Hashimoto; MARCHEZI, Vera Lucia de Carvalho. Português - $6^{\circ}$ ano. Projeto Teláris. São Paulo: Ática, 2012.

MENDES, Ronald Beline. Diminutivos como marcadores de sexo/gênero. Revista Linguística/Revista do Programa de Pós-Graduação em Linguística da Universidade Federal do Rio de Janeiro, v. 8, n. 1, jun. 2012.

ORTHOF, Sylvia. O bisavô e a dentadura. In: BORGATTO, Ana Maria Trinconi; BERTIN, Terezinha Costa Hashimoto; MARCHEZI, Vera Lucia de Carvalho. Português - $6^{\circ}$ ano. Projeto Teláris. São Paulo: Ática, 2012. 
SANDMANN, José Antônio. Formação de palavras no português brasileiro contemporâneo. Curitiba: Scientia et labor: Ícone, 1988.

TRAVAGLIA, Luiz Carlos. Gramática e interação: uma proposta para o ensino de gramática. São Paulo: Cortez, 2009. 